\title{
Comparing Social Isolation Effects on Students Attrition in Online Versus Face-to-Face Courses in Computer Literacy
}

\author{
Azad Ali and David Smith \\ Indiana University of Pennsylvania, Indiana, PA, USA
}

\section{Azad.ali@iup.edu david.smith@iup.edu}

\begin{abstract}
This paper compares the effect of social isolation on students enrolled in online courses versus students enrolled in on campus courses (called in this paper Face-to-Face or F2F). Grade data was collected from one online section and two F2F sections of a computer literacy course that was recently taught by one of the authors of this study. The same instructor taught all sections thereby providing a controlled comparison between the two forms of teaching (F2F and online). This paper first introduces the plan and the limitation of this study. It provides a literature review and notes the trend of social isolation found in online courses. This paper then presents a summary of the collected data; and offers a conclusion based on the collected data.
\end{abstract}

Keywords: Online course withdrawal, social isolation in online courses, attrition in online courses

\section{Introduction}

This study builds on a previous study regarding performance difference between online courses and face to face (F2F) courses. In our first study (Ali \& Smith, 2014) we analyzed the difference in student grades between online courses versus F2F courses. Based on our analysis we determined that student performance in F2F courses is not necessarily superior to online courses. We did note that the rate of withdrawal in online courses is higher than F2F courses. Our inclination was that the withdrawal rate is mainly caused by the social isolation felt among online students. Although our inclination was supported by literature from different studies (Allen \& Seman, 2013, Brown, 2012, Haley \& Heise, 2008, Kirtman, 2009), we did not provide evidence in support of this position. Thus, we decided to research this topic further and to collect data in order to test a general hypothesis about the difference in the feeling of social isolation between students enrolled in online versus F2F courses.

Material published as part of this publication, either on-line or in print, is copyrighted by the Informing Science Institute. Permission to make digital or paper copy of part or all of these works for personal or classroom use is granted without fee provided that the copies are not made or distributed for profit or commercial advantage AND that copies 1) bear this notice in full and 2) give the full citation on the first page. It is permissible to abstract these works so long as credit is given. To copy in all other cases or to republish or to post on a server or to redistribute to lists requires specific permission and payment of a fee. Contact Publisher@InformingScience.org to request redistribution permission.
Social isolation feeling has been examined in various studies and was determined to have effect on the performance of individuals at different levels (Ali \& Kohun, 2007; House, 2001; Pappano, 2001). The feeling of social isolation often starts at the unconscious level and then manifests different ways (House, $2001)$. One of the ways that social isolation manifests on the individual is through attrition from courses or pro- 
grams (Frankola, 2001). Although this can be argued at different levels, social isolation is determined to be a major factor that causes students to dropout in academic courses and programs.

The increased offering of online courses has boosted the level of discussion on the effect social isolation and whether the effect increases among students enrolled in online courses. This study contributes to the on-going discussion by comparing the effect of social isolation on students' attrition in online versus $\mathrm{F} 2 \mathrm{~F}$ courses. It compares withdrawal rate (W grade) from three sections of computer literacy course taught online and F2F by the same faculty member. It drives its conclusion after analyzing the difference of the data collected between these two setting of courses (F2F versus online).

The remainder of this study is divided into the following sections:

- First section defines the problem that this study addresses, establishes the hypothesis and explains the limitation of this study

- Second section provides literature review regarding social isolation and online education

- Third section explains the courses that this study uses and the procedures followed for data collection

- Fourth section analyzes the collected and gives insight into the results

- Fifth section provides conclusion and suggestions for future studies

\section{The Problem}

The problem that this paper is addressing is whether students enrolled in online courses experience social isolation feeling to a greater degree than their counterpart students in F2F courses. A hypothesis can be established to assess the correctness of this problem or not. Also, some limitations are cited regarding the methodology employed in this study.

\section{Hypothesis}

Based on the description above, the problem that this paper is addressing can be stated in terms of hypothetical settings, both in terms of null hypothesis $(\mathrm{H} 0)$ and alternative hypothesis $(\mathrm{H} 1)$. The following is a statement of both hypotheses:

H0: Online students experience social isolation feeling to a greater degree than F2F students in computer literacy courses

H1: Online students do not experience social isolation feelings to a greater degree than F2F students in computer literacy courses

\section{Limitations of This Study}

Three notable limitations are facing this study based on hypothesis, method of data collection, and analysis:

- The collected data is based on one semester of student grades. Although this may be acceptable in some case studies, this narrow scope of data collections makes it challenging to generalize the results and findings of this study.

- The degree of social isolation is based on the measurement of only one factor; the number of withdrawals (W grades) from each section of the course. In our opinion, this is largely true. Our opinion is supported by the findings of other studies that points to feeling of social isolation as the main cause of attrition from courses and programs (Allen \& Seaman, 2008; Harrell, 2008; Hawlery, 2003; Lovitts, 2001). Course withdrawal (attrition) in our opinion is one manifestation of social isolation feeling. 
- We are aware that withdrawal rates (W grades) can be caused by factors other than social isolation, but this study does not address other factors that may cause $\mathrm{W}$ grades. Instead we will focus on the feeling of social isolation and consider it as the grass root for the reasons to withdrawals (W grades) and attrition from online courses.

\section{Literature Review}

Educators agree that online education is here to stay. Most predict the trend of offering of online courses is going to increase substantially given the increasing demand on such courses (Allen \& Seaman, 2008; Beyrer, 2013; Brown, 2012). Yet there is still skepticism about performance of students in online courses in light of the attrition rates among students enrolled (Allen \& Seaman, 2013; Kirtman, 2009). Some note that the feeling of social isolation contributes to the decision to withdraw from their online courses (Parkhurst, Moskal, \& Downey, 2008; Schaeffer \& Konetes, 2010). But the extent to which social isolation has effect on attrition is still not agreed on and may require some background information about these interrelated topics.

To give background information about these issues, this section reviews literature regarding social isolation and the trend in online courses. It begins by describing social isolation feeling in general and addresses the same issue in academic institutions. It continues to show the increasing trend of online education. The section last describes social isolation feeling in online courses in more details to address larger issues with it.

\section{About Social Isolation}

Social isolation has negative effects for the functioning and well-being of individuals, and for solidarity and social cohesion within society. Personal quality of life is very much affected by being part of a social network. By rationalizing relationships, in the public domain, the intimate nature of social relationships in the other domains has become increasingly important. (Hortulanus, Machielse, \& Meeuwesen, 2006, p. 25)

Social isolation is known to have an effect on individuals, on the groups they belong to and on the society at large (House 2001; Hortulanus et al., 2006). There are different explanations about the cause of social isolation and its development. Some point to the upbringing of the individuals and to events in the life of the individuals that lead them to withdraw. Others point squarely to the technological advances that lead the individuals to be more reliant on technology rather than the individual connection (Morahan-Martin, \& Schumacher, 2003). Yet others relate social isolation with the changes of the social structure. For example, Pappano (2001) name this change of structure as "The Connection Gap" and explains the changes in the structure of society are prime factors that increased the risk of becoming socially isolated.

A common description that is mentioned regarding social isolation is a "lack of meaningful social contacts" (Hortulanus et al., 2006). The emphasis here is on the word "meaningful" and its context varies depending on the situation in which it is taking place. At work, meaningful may mean

relationship with peers, superiors, clients, and other individuals that may come in contact with. At colleges and universities, meaningful social contact may take place among students and also between students and faculty members.

Lack of direct contact is considered a contributing factor to social isolation (Priego \& Peralta, 2013). In direct contact the person sees the other individuals face-to-face. All emotions can be felt and expressed at the contact (Ting \& Gonzalez, 2013). No other contact (such as phone, email, and video) can have this direct contact affect (Lehman \& Conceição, 2010). Take a phone conversation for example, there is a voice contact where messages are exchanged and conversations are carried on. Also, some feeling can be detected from the tone of the conversation. But the real feeling that can be viewed from facial expression or body movement cannot be detected in phone 
conversations. Similarly, email messages lack the ability to transmit these emotions. Although a limited extent of feeling can be detected from email messages, feelings cannot be totally epressed in email messages.

The result of social isolation is diverse and multi-faceted. Social isolation may cause anxiety, depression, or withdrawals (Hortulanus et al., 2006). House (2001) went a step further to suggest that the feeling of social isolation may kill people. The results of social isolation can be manifested in the family by having the individual rebel against others in the family or refuse to take part in family activities. At the workplace, it may lead to reduced productivity or unexplained or long absences. At schools and universities, social isolation can show up among students through withdrawal or attrition -dropping out of courses or even programs.

\section{Social Isolation in Academia}

Social isolation has been discussed at various forums in academia and has been described in many literatures. It is also considered a major contributing factor to attrition among students, especially at the graduate level. In terms of doctoral enrollment for example, experts estimate the rate of attrition from doctoral studies is about $50 \%$ and attribute social isolation feeling as the prime factor for such high attrition rate (Ali \& Kohun, 2007; Hawlery, 2003; Lovitts, 2001). This rate of attrition at the doctoral level is especially alarming knowing that most students who attend doctoral programs are high achievers as they start doctoral studies after long successes in their earlier studies. Thus, academic preparedness is not considered a major drop out factor for doctoral students (Hawlery, 2003; Lovitts, 2001).

At the undergraduate level, similar feelings of social isolation emerge that cause the students to drop out of their courses and programs. Academic institutions are active in their attempts to tackle this issue. They typically take proactive measures that aim in part to limit the effect of social isolation and encourage social integration into the academic community. Among these proactive steps are forming social clubs and planed social events to encourage social communication and interaction among students.

The increased use of technology makes it easier for students to rely on technology instead of communicating with others (Top, 2012). This decreases the need for direct communication with others. It, in turn, increases the chance to cause social isolation. In other words, if the student spends significant portion of the time dealing with the machine (the computer) alone, then it lessens the chance of meeting and talking directly to people. This in turn creates a recipe for the student to be socially isolated.

Online education is one of the results of advances in technology. Students can complete courses and programs without the need to see any of their professor or their colleagues. They may not have to socialize with others. Initially, online attrition was not seen as a major problem for students and for the completion of their degrees because the number of courses that were offered used to be limited. Recent increase of online courses offerings changed this perception (Morris \& Finnegan, 2005). The increase of online offerings is persistent and is inclusive of most fields of study (Monolescu, Schifter, \& Greenwood, 2004). To understand the severity of the problem of social isolation in online courses, we need to understand the trend of online enrollment, online course offering, and online education in general.

\section{About Online Education - Enrollment Trend}

There is a steady increase in the number of online course offerings. This is reflected in the number of courses offered online, the number of students taking online courses, and the number of programs and institutions that offer online courses (Monolescu et al., 2004; Morahan-Martin \& 
Schumacher, 2003). This also is reflected in comparing the growth in total student population versus growth in students taking online courses.

Allen and Seaman (2013) conducted a survey to study the trend in online learning in all of the United States between the years of 2002 and 2011. The result of their study was tabulated in different ways and one of these tables is shown in Figure 1. The figure shows the annual growth rate in total enrollment versus enrollment in online course. The last column gives a clearer picture of this trend. It shows that online enrollment is increasing steadily by at least $9.6 \%$ and as high as $32 \%$ annually. This average to $17.3 \%$ annually in online enrollment compared with $2.6 \%$ growth rate increase experienced in total enrollment of student population during the same period.

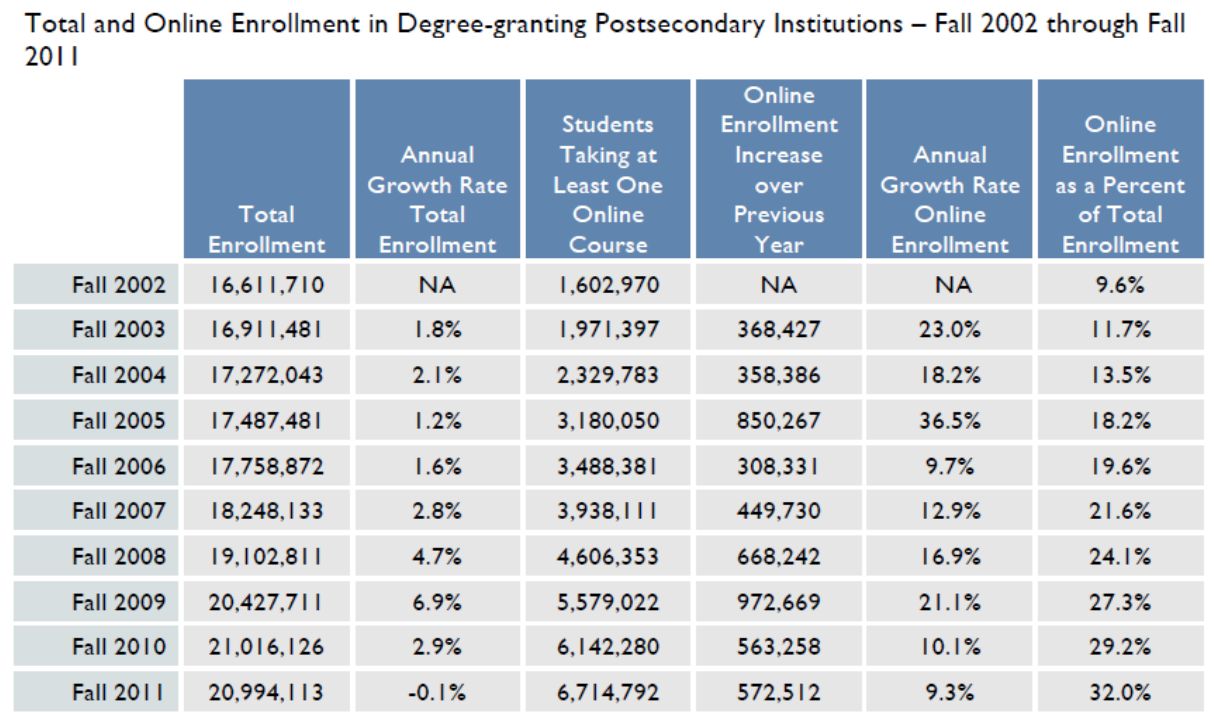

Figure 1 - Enrollment Trend online Versus F2F (Source: Allen \& Seaman, 2013)

Figure 2 shows graphical representation of online enrollment as a percentage of total enrollments over the span of the survey years. It shows that this percentage increased from about $9 \%$ in 2002 to more than $30 \%$ ten years later in 2011 . The bar and the figure for year 2011 shows that online enrollment represent about one third of total enrollment among all student population.

Online Enrollment as a Percent of Total Enrollment: Fall 2002 -

Fall 20II

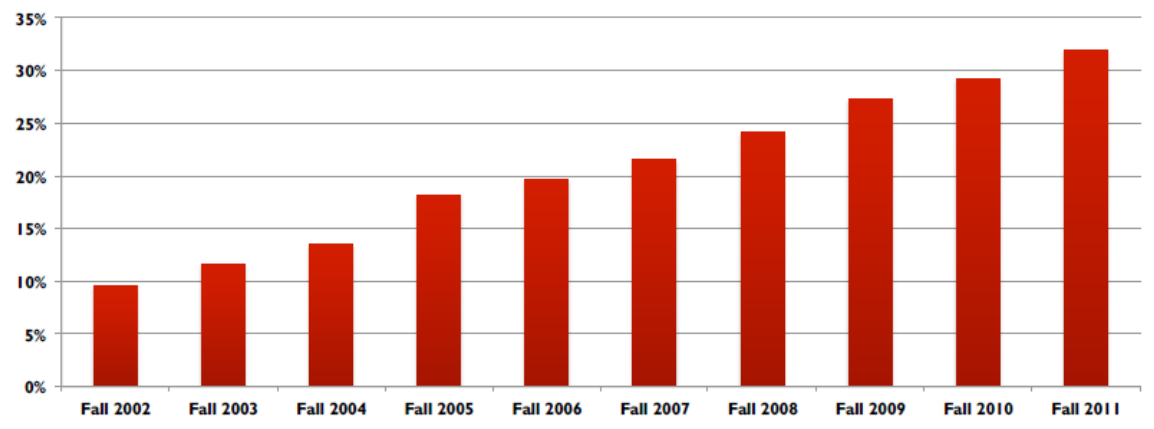

Figure 2 - Online enrollment as a percentage of total enrollments (Source: Allen \& Seaman, 2013)

In an earlier study, Allen and Seaman (2008) compared total enrollment in online course between graduate course, undergraduate courses, and other courses. They found that undergraduate cours- 
es represent the highest number of total online courses. They also found that the size of institution also affects the number of online courses offered by it. Institutions with higher number of student population offer a higher percentage of online courses (see Figure 3).

Mean Online EnRollment by Size of INStitution - Fall 2007

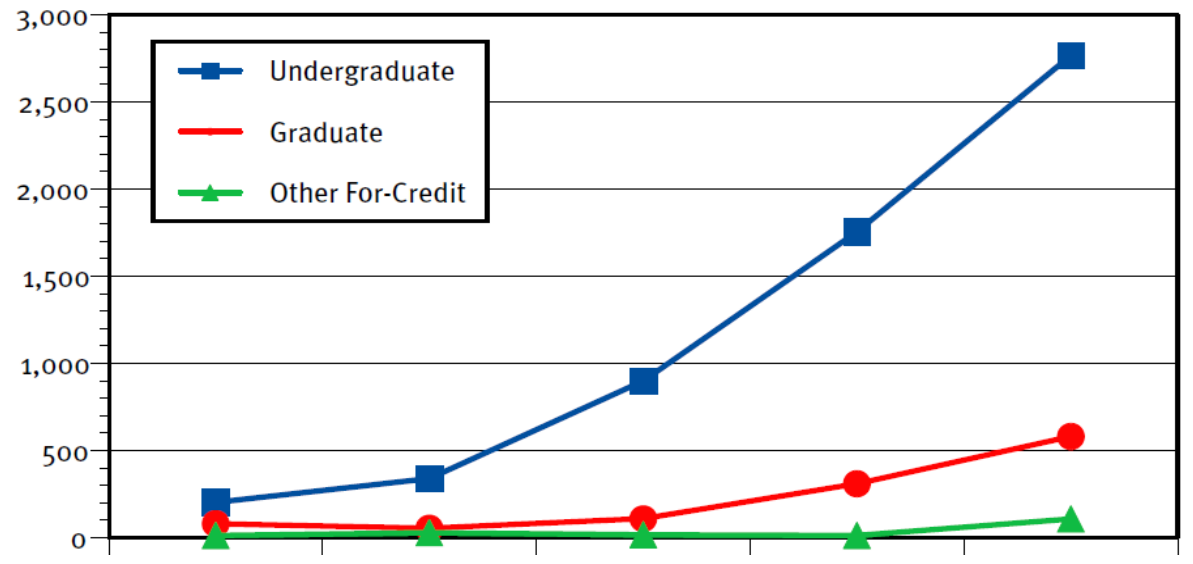

Figure 3 - Enrollment Trend online Versus F2F (Source: Allen \& Seaman, 2008)

The increase of online enrollment is not limited to the years shown in Figures 1, 2 and 3, instead various studies show that there is a continuous trend of increase in online courses. This includes the increase in number of courses offered and also in the number of students taking online courses. Beyrer (2013), for example, reported that only 376 students were enrolled in online courses in 2001 in his institution. This number increased to 5289 students taking one or more online courses in the fall of 2012 in the same institution. This represents an increase of 1,307\% in students enrolled in online courses between 2001 and fall of 2012. Varner (2013) noted that in 2008 the overall undergraduate student population in the US increased by $1.2 \%$ but the number of students taking online courses increased by $17 \%$. Similar increases were reported in 2010 when the online enrollment increased by $10 \%$ and the student population increased by $1 \%$. These numbers show that the increase in online enrollment significantly outpaced the growth in the overall student population (and also those taught in F2F courses). In terms of actual number of students taking online courses, Kirtman (2009) estimated 3,077,000 students were enrolled in all distant education courses in the US in 2001-2002. Likewise, Luo, Pan, Choi, Mellish, and Strobel (2011) reported over 4.6 million students were taking a least one online course in 2008.

\section{Social Isolation in Online Education}

Although online education has been continually increasing, there is wide spread concern among educators and students alike regarding two issues for online education: the quality of education and the rate of attrition in online courses. First, they feel that online courses do not offer the same quality as F2F courses. Second, attrition rates are higher among online students than among students in F2F courses (This we supposed at the beginning of this study is caused by the feeling of social isolation among online students).

Schaeffer and Konetes (2010), for example, explained that students enrolled in online programs drop out of their programs at higher rates than students in on-site delivery. They also report the feeling of social isolation as the main factor that was cited by the students as a reason for their dissatisfaction with their programs. 
Allen and Seaman (2012) noted that a continuing concern among academic leaders at all types of institutions has been their belief of a lower retention rates in online courses. They report that this is a major barrier to the growth of online education.

The rate of attrition from online courses is higher than regular F2F courses. Frankola (2001) reported that most people in the e-learning industry do not talk about this issue of high attrition rate in online education. Frankola reported that attrition rate is about $20 \%-50 \%$ in online education compared to $10 \%-20 \%$ in regular F2F courses.

Although the concern for online retention is widespread among academies, hard evidence comparing to retention with F2F courses is not immediately available. This paper makes this data available through the case study and the data it collected in this case. The following section explains the case, how the data was collected, and then presents analysis of the data.

\section{The Case}

This study used data from three sections of a course taught by a faculty member at Eberly College of Business at Indiana University of Pennsylvania. The faculty member taught three sections of a computer literacy program (BTED101 Computer Literacy) in the spring 2014 semester - two F2F and one online. A total of 114 students enrolled in the three sections of the course. In this study, we will be using the number of withdrawals (W grade) from these courses to measure the social isolation level felt by the students in the online section versus the F2F section of the course.

The course BTED101 - Computer Literacy is a three credit first year course that does not have any pre-requisite. Students can take this course online or F2F. The course is divided into two main sections: computer theory and computer applications. The theory section covers theoretical background on computers, their components, categories, classifications, and other related topics. The applications section covers four major software applications: word processing, spreadsheet, presentations, and database management systems. Assignments were given for each of the applications.

Assessment for this course is based on two exams (midterm and final) for the theory sections and five assignments to cover the application section. There is one other liberal study requirement regarding this course - a book reading. The faculty assigns the students to prepare a report after reading a book.

The following is the distribution of the grades for all the sections of this course

$\begin{array}{ll}\text { Homework and/or lab assignments } & 45 \% \\ \text { Exam1 } & 20 \% \\ \text { Book Reading Report } & 10 \% \\ \text { Exam2 } & 25 \%\end{array}$

The same assignments were given to all three sections of the class, and questions for the two exams were based on the same database pool of questions. Deadlines for the same assignment were identical and the same textbooks were used for all three sections of the course. Also, the same software and textbook examples were used in both the online and F2F sections of the course. Knowing that all things (textbooks, assignments, exam, others) were the same, one may assume that the performance and the retention rate is going to be the same for all three sections of the course. However analysis of the data from the students' grades showed something different.

There is one notable difference between the form of delivery (online and F2F) in attendance policy. The F2F course requires the students to attend classes. If a student misses more than a week of classes without excuse, the student grade drops one level (for example from B to C). If a student misses two or more weeks of classes, the student automatically receives a failing grade. No such 
attendance policy is included in the online course simply because it is not possible to enforce such policy in online courses. Some may argue that the inclusion of this policy helped with attendance for F2F students and, therefore, helped minimize the effect of social isolation. This assumes that attending classes regularly allows for more direct contact and may minimize the chance of feeling socially isolated. However, we can counter that in online courses this form of attendance policy is difficult to enforce, and thus we excluded such policy in the online course.

\section{Data Collection and Analysis}

The paper bases its recommendations on the final grades for the three sections of the computer literacy course that were used in the case for this paper. Students' final grades were completed and distributed. It was then tabulated by numbers of students and their withdrawals (W grades).

Table 1 shows the calculation of the grades for the students enrolled in the courses that were taught by this faculty member. The first two columns show the course and section numbers, and then the number enrolled in each section of the course. The next column shows the number of W grades for each section. The last column shows the percentage of students withdrew from each section of the course. This is calculated by dividing the number $\mathrm{W}$ grade (third column) by the number students enrolled in the course (second column).

Table 1 - Students Withdrawals Data

\begin{tabular}{|l|c|l|c|}
\hline Course and Section & $\begin{array}{l}\text { Number Students } \\
\text { Enrolled }\end{array}$ & $\begin{array}{l}\text { Number Withdrawal (W) } \\
\text { Grade }\end{array}$ & \% withdrawal grade \\
\hline BTED101 001 & 44 & 2 & $5 \%$ \\
\hline BTED101 002 & 40 & 0 & $0 \%$ \\
\hline BTED101 801 (Online) & 30 & 5 & $17 \%$ \\
\hline
\end{tabular}

\section{Conclusion and Suggestion for Future Studies}

Based on the data collected and presented in Table 1, the null hypothesis that was made earlier in this paper is accepted. The evidence presented in this study points that withdrawal rates in online courses is higher than F2F courses. We made a note earlier that we are going to use the withdrawal rate in the courses to measure the social isolation experienced by the students in the courses mentioned. Thus, a conclusion can be made in this study that online students in computer literacy classes experience social isolation at higher levels which influences their decision to withdraw from the courses they take.

Based on the results from both of our studies that we conducted here, we realize that the data we used in the studies is limited and therefore cannot be fully generalized. Thus, we intend to extend our study by adding data over a longer span of semesters for the same course. Furthermore, we intend to include data from the same courses that are taught by another colleague (both online and F2F). By collecting data from more semesters and including more literature, we believe that our result will be more generalizable. Thus we intend to tackle both issues (social isolation and performance measures) in online courses versus F2F courses in a future study.

\section{References}

Ali, A., \& Kohun, F. (2007). Dealing with social isolation to minimize doctoral attrition - A four stage framework. International Journal of Doctoral Studies, 2, 33-49. Retrieved from http://www.ijds.org/Volume2/IJDSv2p033-049Ali28.pdf

Ali, A., \& Smith, D. (2014). Comparing students performance in online versus face-to-face courses in computer literacy courses. Competitiveness Forum, 12(2), 118-123. 
Allen, I. E., \& Seaman, J. (2008). Staying the course: Online education in the United States, 2008. ERIC.

Allen, I. E., \& Seaman, J. (2013). Changing course: Ten years of tracking online education in the United States. Babson survey research group.

Beyrer, G. M. (2013). Online student success: Making a difference. Journal of Online Learning and Teaching, 6(1), 1-21.

Brown, J. M. (2012). Online learning: A comparison of web-based and land-based courses. Quarterly Review of Distance Education, 13(1), 39-42.

Frankola, K. (2001). Why online learners drop out. Workforce, 80(10), 52-60.

Haley, K. L., \& Heise, K. (2008). Building the successful online course. Charlotte, NC: IAP-Information Age Pub. Inc.

Harrell, I. L. (2008). Increasing the success of online students. Inquiry, 13(1), 36-44.

Hawlery, P. (2003). Being bright is not enough. Springfield, IL: Charles C. Thomas.

House, J. (2001). Social isolation kills, but how and why? Psychosomatic Medicine. 63, 273-274.

Hortulanus, R., Machielse M., \& Meeuwesen, L. (2006). Social isolation in modern society. New York, NY: Routledge.

Kirtman, L. (2009). Online versus in-class courses: An examination of differences in learning outcomes. Issues in Teacher Education, 18(2), 103-116.

Lehman, R. M., \& Conceição, S. C. O. (2010). Creating a sense of presence in online teaching: How to "be there" for distance learners (1st ed.). San Francisco: Jossey-Bass.

Lovitts, B. E. (2001). Leaving the ivory tower: The causes and consequences of departure from doctoral study. Lanham, MD: Rowman \& Littlefield.

Luo, Y., Pan, R., Choi, J. H., Mellish, L., \& Strobel, J. (2011). Why choose online learning: Relationship of existing factors and chronobiology. Journal of Educational Computing Research, 45(4), 379-397.

Monolescu, D., Schifter, C., \& Greenwood, L. (2004). The distance education evolution: Issues and case studies. Hershey, Pa.: Information Science Pub.

Morahan-Martin, J., \& Schumacher, P. (2003). Loneliness and social uses of the Internet. Computers in Human Behavior, 19(6), 659-671.

Morris, L. V., Xu, H., \& Finnegan, C. L. (2005). Roles of faculty in teaching asynchronous undergraduate courses. Journal of Asynchronous Learning Networks, 9(1), 65-82.

Pappano, L. (2001). The connection gap: Why Americans feel so alone. New Brunswick, NJ: Rutgers University Press.

Parkhurst, R., Moskal, B., M., Downey, G., L (2008). Engineering cultures: Online versus in-class. MERLOT Journal of Online Learning and Teaching, 4(4), 438-445.

Priego, R. G., \& Peralta, A. G. (2013). Engagement factors and motivation in e-learning and blendedlearning projects. In Proceedings of the First International Conference on Technological Ecosystem for Enhancing Multiculturality (pp. 453-460).

Schaeffer, C. E., \& Konetes, G. D. (2010). Impact of learner engagement on attrition rates and student success in online learning. International Journal of Instructional Technology \& Distance Learning, 7(5), 3-9.

Ting, S., R.; Gonzalez, L., M. (2013). Quality of interactions in face-to-face and hybrid career development courses: An exploration of students' perceptions. Journal of Online Learning \& Teaching, 9(3).

Top, E. (2012). Blogging as a social medium in undergraduate courses: sense of community best predictor of perceived learning. The Internet and Higher Education, 15(1), 24-28. 
Varner B. (2013). Undergraduate perceptions of online coursework. Journal of Applied Learning Technology, 3(1), 16-20. Available from: Computers \& Applied Sciences Complete, Ipswich, MA. Accessed March 4, 2014.

\section{Biographies}

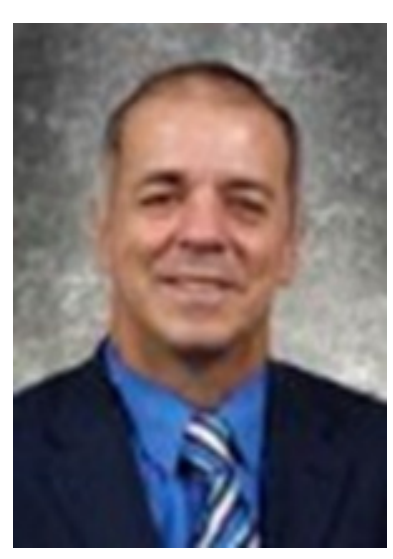

Azad Ali, D.Sc., Professor of Information Technology at Eberly College of Business - Indiana University of Pennsylvania - has 30 years of combined experience in areas of financial and information systems. He holds a bachelor degree in Business Administration from the University of Baghdad, an M.B. A. from Indiana University of Pennsylvania, an M.P.A. from the University of Pittsburgh, and a Doctorate of Science in Communications and Information Systems from Robert Morris University. Dr. Ali's research interests include service learning projects, web design tools, dealing with isolation in doctoral programs, and curriculum.

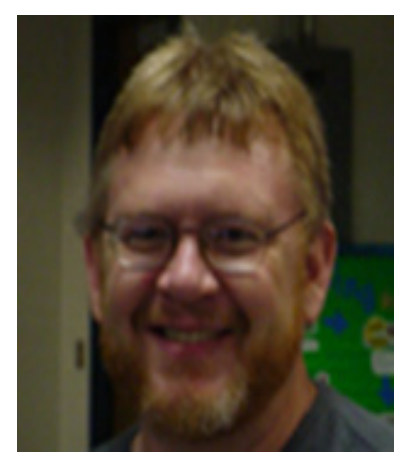

David T. Smith, Ph.D., Associate Professor of Computer Science Indiana University of Pennsylvania - has 12 years' experience in academia and 21 years of industry experience in database systems, computer language development, and other systems programming. He holds a bachelor degree in Physics and Mathematics Education from Indiana University of Pennsylvania, an M.S. in Computer Science from University of Central Florida, and a Ph.D. in Computer Science from Nova Southeastern University. Dr. Smith is active in consultancy and has research interests in artificial intelligence, distributed object computing, data mining, and software engineering. 